DOI: 10.17805/zpu.2017.2.9

\title{
Телесно-ориентированный подход при анализе произведений экранного искусства
}

\author{
А. А. ДЕНИКИн \\ ИНСТИТУТ КИНО И ТЕЛЕВИДЕНИЯ (ГИТР), Г. МОСКВА; \\ РОССИЙСКИЙ ГОСУДАРСТВЕННЫЙ ГУМАНИТАРНЫЙ УНИВЕРСИТЕТ
}

В статье анализируются основные положения зарубежных исследований экранных произведений в рамках телесно-ориентированного подхода. Рассматриваются философские работы А. Бергсона, М. Мерло-Понти, Д. Кампера, У. Матурана, Б. Массуми, Ф. Варела, М. Хансена и др. На основе телесно-ориентированного подхода и концепции «телесно воплощенной симуляции» в статье рассматривается роль аффективного, телесного опыта при интерпретации аудиовизуальных произведений. Утверждается, что сама «визуальность» мира формируется скорее внутренними телесными элементами, нежели абстрактной властью взгляда, причем именно тело зрителя и его активность задают условия для восприятия образов.

Анализируется новый тип чувствования, когда субъект определяется отнюдь не разумом, но своей телесностью, именно она центрирует и конституирует его. Телесный уровень чувствования, аффективное переживание/опыт полнее и аккуратнее отражают характеристики индивидуальности, нежели процессы на более высоких уровнях сознания, как 
правило, подлежащих/подчиненных в своей работе разнообразным опосредующим режимам сигнификации. В результате человеческое тело воздействует само на себя через собственную аффектацию, производя внутреннее эмоциональное пространство «я», не ограниченное перцепцией или работой какого-либо отдельного органа чувств.

Теория «телесной симуляции» обеспечивает научные, нейробиологические основания для понимания специфики взаимодействия между зрителем, автором и экранным произведением. Обсуждаются возможности мультисенсорного восприятия образов кинематографических произведений. Предлагается рассматривать рецепцию произведения как процесс зрительского действования в иллюзорной и пространственно локализируемой среде.

Визуальные образы расширяют возможности самореализации зрителя посредством телесной активности, делают разнообразнее его «внутренние действия» в перцептивном (аффективном) опыте проживания «внутреннего пространства». Воспринимая произведение, зритель энактивирует экранное пространство, открывая для себя возможности действий собственного тела. Восприятие понимается в его синкретичной связи с действием, психомоторной активностью (активностью психики и тела) и активностью ума, концептуализацией. Даже ментальная активность понимается как действие или как движение.

Делается вывод о том, что проблема телесности, «телоцентризма», «соматизма» выходит на передний план искусствоведческой и в целом гуманитарной рефлексии, поскольку позволяет искать пути преодоления смысловой избыточности культурных объектов и художественных произведений.

Ключевые слова: телесно-ориентированный подход; гаптическая эстетика; аффективность; образ-аффект; мультимодальность; зеркальные нейроны; телесно воплощенная симуляция; энактивизм; энактивное познание

\section{ВВЕАЕНИЕ}

Господство зрения настолько глубоко укоренено в логоцентричном сознании 1 современного человека, что любое произведение, любой образ, да и сама репрезентация традиционно осмысливаются преимущественно с опорой на видение, на зримое.

И философы древности, и последующие философские школы выстраивали иерархию пяти человеческих чувств в зависимости от возвышения духа над телом, интеллекта над эмоциями. Зрение и слух - это дистанционные чувства, так как действуют на расстоянии от своих объектов и не требуют физического взаимодействия с ними. Разделение между телом воспринимающего и объектом восприятия создает выгодную «остраненную» эпистемологическую позицию, поэтому зрение и слух обычно ставились на вершину иерархии из-за их важности для получения знаний об окружающем мире и передачи этих знаний другим людям.

Так называемые телесные (гаптические) чувства вкуса, обоняния и осязания, напротив, требуют физического контакта с объектом. Хотя обоняние и предполагает некоторое физическое удаление объекта, всем трем чувствам необходима близость объекта, даже соприкосновение, и опыт всех трех чувств имеет выраженную чувственную окраску. Физиология, связанная с осязанием, обонянием и вкусом, является причиной низкого статуса телесных чувств, ассоциируемых с животной стороной человеческой натуры. Вероятно, поэтому, изящные искусства (живопись, музыка, скульптура, поэзия и пр.) в западноевропейской традиции преимущественно обращены к зрению и слуху, но не к «телесным» ощущениям - осязанию, обонянию и вкусу.

Художественные практики XX в. (фотография, кино, видео, телевидение и пр.) преимущественно опираются на зримое и на слышимое. В классической кинотеории визуальные и звуковые образы фильма наделяются самостоятельностью и объектив- 
ностью, они должны нести в себе предзаданную автором «эстетическую экспрессию», нацелены на воздействие на зрителя/слушателя, должны передавать ему эстетические значения, знаки и смыслы через форму артефакта/текста.

Аолгое время считалось, что зритель физически «пассивен» и обездвижен в своем кресле в кинозале, следовательно, приоритетными для восприятия аудиовизуального произведения являются работа сознания и когнитивные процессы, обусловленные визуальными и семиотическими особенностями изображений. Отказ от рассмотрения телесной активности зрителя неизбежно приводил исследователей к наделению самого кинообраза «активным началом», выделению аппарата кино как машины воздействия и обсуждению «машинной функции» движущегося изображения как проекции зрительского сознания (Аелез, 2004; Морен, 1996; Guattari, 1995).

Переосмысление роли зримого в философских и художественных практиках XX в. привело к ряду так называемых поворотов: «лингвистическому», «визуальному», «медиальному», «телесному» и пр. (Савчук, 2010).

Попытки преодоления оптикоцентричности (доминирования визуального канала восприятия информации) привели к формированию так называемого холистического мировоззрения, получившего название телесно-ориентированного подхода (англ. the embodied cognition approach). Он основывается на философских идеях А. Бергсона, М. Мерло-Понти, А. Кампера, исследованиях У. Матурана и Ф. Варела, М. Хансена и др. Популяризация отдельных идей и теоретических положений «телоцентризма» осуществляется в работах М. Эпштейна и Г. Тульчинского (Эпштейн, Тульчинский, 2006).

В рамках телесно-ориентированного подхода подчеркивается роль аффективного, телесного опыта в интерпретации аудиовизуальных произведений.

Целью этой статьи является рассмотрение зарубежных исследований в рамках телесно-ориентированного подхода и концепции «телесно воплощенной симуляции» для подтверждения гипотезы о том, что сама «визуальность» мира формируется скорее внутренними телесными элементами, нежели абстрактной властью взгляда, причем именно тело зрителя и его активность задают условия для восприятия экранных образов. Аля подтверждения гипотезы анализируются возможности мультисенсорного восприятия образов кинематографических произведений.

\section{ТЕАЕСНОЕ ВОСПРИЯТИЕ ОБРАЗА: \\ К МУАЬТИСЕНСОРИКЕ АОАИСКУРСИВНОГО АФФЕКТА}

Художники и мыслители уже в начале ХХ в. фиксировали ограниченность категорий кантианской эстетики, доминировавшей в традиционных представлениях об искусстве. Они утверждали, что общая рационализация мышления и потеря связи искусства с человеческой телесностью ведут к неестественному, к неприродному разделению человеческого сенсориума, к схематизации работы перцепции, к ошибочной автономии образа и к представлениям об искусстве как сфере обмена эстетизированными объектами.

Интерес к непосредственно телесному, висцеральному воздействию кино проявляли как критики, так и практики кино. Так, Б. Балаш (рассматривал кино в качестве гносеологического средства) и А. Вертов (представлял киноаппарат как анимистическое устройство) признавали важность тесной связи между телом зрителя и воздействующими на него кинообразами (Балаш Б., 1925; Азига Вертов: Киновещь, 2016).

На раннем этапе становления киноискусства В. Беньямин публикует свое ставшее знаменитым әссе «Произведение искусства в эпоху его технической воспроизводимо- 
сти» (1936) о техниках репродукции в искусстве. Беньямин определяет «ауру» произведения как след предыдущего материального контакта художника, будь то мазок кисти художника-живописца или бронзовое изваяние, сохранившее каждый изгиб, в свое время приданный ей рукой скульптора. Аура способствует соприсутствию между зрителем и объектом созерцания: «здесь и сейчас» оригинала определяют возможность их прямого контакта посредством органов чувств зрителя. Аура произведения реализует дистанцирование субъекта внимающего (реципиента опыта) от предмета созерцания (объекта опыта).

Но технологии воспроизведения образа нарушают эту дистанцию, разрушают ауру произведения - «уникальное ошущение дали». Технология превращает кино в развлекательную стихию, визуальность которой носит, по мнению Беньямина, «тактильный характер». Технически репродуцированное изображение и артефакты дадаистов объединяет тенденция к тактильности как при восприятии, так и при создании. Утерянная аура способствует установлению тактильного контакта между зрителем и фильмом: «Из манящей оптической иллюзии или убедительного звукового образа произведение искусства превратилось у дадаистов в снаряд. Оно поражает зрителя. Оно приобрело тактильные свойства» (Беньямин, 1996: 57).

Феноменологический подход к исследованию кино признает взаимоположенность, взаимодействие, взаимовлияние субъекта и объекта кинематографического опыта. Кинофеноменологи (например, В. Собчак, М. Ямпольский) показывают, что киновосприятие, будучи обусловленным материальной спецификой человеческой телесности, принципиально не отличается от любых других форм перцепции, поскольку восприятие «основывается на субъективности, заключенной в живое тело» (Sobchack, 2004: 66).

В своем труде «Феноменология восприятия» французский феноменолог М. Мерло-Понти доказывал, что любое восприятие - это телесное восприятие, и зрение не может функционировать отдельно от человеческого тела, которое собственно и делает возможным видение. Аля Мерло-Понти сенсорный опыт предопределен самой плотью, телесностью и исторически сложившимися структурами жизни тела в мире. Поэтому, по его мнению, кино - это феноменологическая практика, поскольку «кино исключительно приспособлено к выявлению союза духа и тела, духа и мира и выражения одного в другом» (Мерло-Понти, 1999: 15).

В. Собчак настаивает на обязательном рассмотрении выразительности кинофильма в контексте его взаимодействия с телесностью зрителя, чье видение уже «заранее знает», заранее «информировано» данными телесного восприятия (Sobchack, 2004: 60). Авижение камеры, смена кадров - это не только признак механической работы прибора, это еще и объект зрительного восприятия, а также и предмет, который видит, движется и выражает восприятие (автора, оператора, субъекта и пр.). Тем самым камера постоянно создает и сглаживает напряжение между видимым и телесным.

Собчак пытается утвердить особый подход к пониманию кинематографического опыта, который основан не на традиционном определении мимезиса, а на понятии «контакт». Контакт понимается как комплексный висцеральный и перцептивный опыт, получаемый при соприкосновении «тела образа»и «тела зрителя». Элементы экранного изображения и кинематографической выразительности должны войти в перцептивный, аффективный резонанс с телом зрителя, «энергетические импульсы» фильма должны передаться через осязаемое кинематографическое пространство, через «мысли плоти» (Sobchack, 2004: 60), говоря словами В. Собчак. 
Французский философ Ж. Аелез, выступая против лингвистического и психоаналитического подходов в киноисследованиях, указывал, что кино одновременно и материально, и не материально, оно есть форма становления, а не форма сигнификации или точной передачи значения, оно есть форма «имманентного бытия», в котором материя, движение и сознание неразрывно связаны. В своих рассуждениях о кино Аелез обращается к данным нейрокогнитивной науки, к физиологическим основаниям работы человеческого мозга. В одном из интервью, опубликованном под названием «Мозг - это экран», он утверждает: «Я не верю, что лингвистика и психоанализ подходят для анализа кино. Напротив, биология мозга -молекулярная биология подходит» (The Brain Is the Screen, 2000: 366).

Продолжая критическую и феноменологическую линию философии, американский философ и художник М. Хансен стремится утвердить особую методологию исследования современного искусства и цифровых практик художников, в которой медиатехнологии не лишают человека субъектности, телесность не задается и регулируется, а, напротив, восприятие и самосознание субъекта определяются его телесностью. Хансен находит аргументы в пользу своей теории в работах французского философа А. Бергсона, а также в исследованиях современных лингвистов-когнитологов - например, Ф. Варела, Э. Хатчинса, Э. Кларка, А. Аамасио и др.

Хансен фиксирует парадигмальный переход в современной гуманитарной науке от визуальности к аффективности, от окуляроцентризма к «гаптической әстетике», определяемой телесной аффективностью. Вместо кинематографического кадра и рамы киноэкрана Хансен провозглашает человеческое тело как средство актуализации, фильтрации и обработки образа и информации: «аффективная телесность» зрителя как граница, как «рама», оформляющая информацию. «Тело приобретает функцию селективного процессора информации <...> возможности дигитализации способствуют возврату от рамочной специфики медиальных интерфейсов к телесности, в которой медиальность и зародилась» (Hansen, 2004: 21).

Хансен излагает свою концепцию «телесной аффективности» в идейном споре с философом Ж. Аелезом, ссылаясь на философские и научно-исследовательские идеи А. Бергсона.

В работах «Опыт о непосредственных данных сознания» (Бергсон, 1992) и «Материя и память» (Бергсон, 1992) Бергсон связал процесс восприятия человеком окружающего мира и себя в нем не только с особенностями чувственных рецепторов субъекта, но и с его внутренними потребностями и вызываемыми ими действиями. С точки зрения Бергсона, сама природа человеческого восприятия снимает необходимость традиционного картезианского противопоставления субъекта и объекта, души и тела, сознания и материи. Аля Бергсона человеческие ощущения не зависят всецело от нервной системы человека. Они подвержены воздействию аффекта, аффектированы, но ощущения и аффект - не одно и то же.

Согласно концепции Бергсона, восприятие отнюдь не создает образы, оно лишь устраняет (фильтрует) из их совокупности те, которые не удовлетворяют телесной потребности, и оставляет удовлетворяющие этой потребности. В качестве условия выбора конкретного образа Бергсон помещает человеческое тело, которое он определяет как «центр индетерминации образа». Восприятие произведения является телесным усилием выбора конкретного образа из потенциального множества образов, а цель восприятия - подготовить реакцию тела и наметить его действия. Задержка передаваемого выбором движения становится (или называется) восприятием - и по- 
средством этого осуществляется селекция или выделение конкретного образа из индифферентного потока образов ( «универсума смыслов»).

Авижение, которое передается и превращается в немедленную физическую реакцию (сенсорно-моторную реакцию), по мнению Бергсона, не создает восприятия. Аишь задержанное, неопределенное (и неопределившееся) действие становится им. Задержка, возникающая в живом организме, оказывается в некотором роде «экраном», который заставляет проявиться тот единственный образ, который и становится воспринимаемым образом. Расширение зоны неопределенности (индетерминации) для Бергсона есть усиление качества восприятия.

Бергсон связывает восприятие с действием, телесным движением. В работе «Творческая эволюция» Бергсон пишет: «...наша мысль изначально связана с действием. Именно по форме действия был отлит наш интеллект» (Бергсон, 1998: 75). То есть, согласно рассуждениям Бергсона, зрение, как и любая другая модальность человеческого опыта, взаимосвязано с гаптическим и кинестетическим ощущениями телесного действия. Следовательно, никакая репрезентация образа не в состоянии зафиксировать все возможные его качества. Восприятие образа зависит от «действия тела», воспринимающего субъекта.

В своем основательном труде о кино французский философ Ж. Аелез обнаруживает применимость философских положений Бергсона к анализу конкретных примеров работ кинематографистов (Аелез, 2004).

В «Кино 1» Аелез предположил, что функция монтажа в кино аналогична бергсоновскому пониманию работы человеческого тела как «центра индетерминации», когда сознательное усилие зрителя «выбирает» образ из индифферентного потока образов, в результате чего зритель испытывает эмоции. Однако для Аелеза полем действования становится не тело и его усилие, а сам кадр и его границы - фрейминг. Аля Аелеза образ оформляется границами кадра: независимо - фотография это, кино, видео или телевидение образ автономен от воспринимающего субъекта. А интервал между монтажным соединением двух кадров в кино представляет «промежуток между действием и реакцией» (там же: 60).

Аелез утверждает, что «образ-движение» вызывает особый режим восприятия фильма (так называемую сенсорно-моторную ситуацию), при котором зритель вовлекается в экранное действие благодаря идентификации с персонажами и самим экранным действием. По мнению Аелеза, характер взаимодействия между образом-движением и зрителем по большей части механический: фильм нацелен на то, чтобы вызвать определенные ощущения в зрителе (пример: эйзенштейновский принцип «монтажа аттракционов»). Как считает Аелез, мы не имеем возможности воспринимать «образдействие» так, как хотим сами, а лишь так, как сам образ «позволит» нам воспринимать себя. То есть определенные психологические реакции зрителя предопределены самими образами кино. Например, если мы видим на экране ружье, это дает основание полагать, что рано или поздно оно выстрелит. Вся логика последующих событий фильма окажется связанной с самим образом ружья.

«Образ-время», речь о котором у Аелеза идет в его книге «Кино 2», напротив, не связан с какой-либо предзаданной образной структурой, требует ассоциативного восприятия, обращения к памяти зрителя, его воображению. Этот образ, который, по мнению Аелеза, появляется в некоторых кинофильмах послевоенного периода середины XX в., начиная с итальянского неореализма, не связан с причинностью и линейным временем: время разворачивания образа не подчинено авторской логике, оно не 
подчинено времени әкранного действия и монтажному времени экранного повествования. Зрителю предлагается исследовать «образ-время» по-своему, вне механической сенсорно-моторной предзаданности проекций-идентификаций «образа-движения» (как, например, в фильмах М. Антониони, В. Вендерса и др.). Аелез утверждает, что в фильмах с «образом-временем» сам процесс всматривания, смотрения доминирует над повествованием и экранным действием.

Аля Аелеза «образ-время» ближе всего к «универсальному потоку образов» в понимании Бергсона. Согласно Аелезу, такие образы становятся чистыми «образамиаффектами» (affection-image), соприродными самому движению «потока индетерминации» и его внутреннего времени. Аелез определяет образ-аффект как один из компонентов человеческой ментальности, занимающий промежуточное положение между перцепцией и действием (физическим откликом на раздражитель).

Аля Аелеза «образ-аффект» в кино - особенный, потому что он резонирует с сознанием зрителя до того, как проявлены какие-либо движения тела. «Образ-аффект» позволяет уйти от физиологического воздействия «образа-движения» в область «чистого» воображения и ментальной свободы зрителя. Аффектация для Аелеза есть то, что заполняет интервал, позволяет телу зрителя как «центру индетерминации» задерживать сенсорно-моторные действия и тем самым вызывать необычные эмоциональные реакции. Поэтому для Аелеза аффектация - это часть механизма работы перцепции.

Такое положение вступает в противоречие с бергсоновской концепцией аффектации, которая представлялась Бергсону как телесный феноменологический модус, не ограниченный данными человеческой перцепции, а содетерминированный ею.

М. Хансен показывает, что Аелез искажает бергсоновскую концепцию телесности как основания для человеческой перцепции. Признание Аелезом первичности образа, его функционирования в качестве «центра индетерминации» приводит к тому, что у Аелеза сам образ определяет зрительскую перцепцию, а не перцепция, основываясь на «опыте тела», определяет образ (как у Бергсона).

Когда фрейминг в кино и обусловленная его спецификой работа сознания человека (а вовсе не человеческое тело) выполняют роль «центра индетерминации» образа (позиция, поддерживаемая Ж. Аелезом), то очевидным становится (и это констатирует сам Аелез), что сам аппарат кино («образ-движение», «образ-время») выходит за грань человеческого уровня перцепции, определяется «машинным видением», постгуманистическими режимами функционирования чувств и сознания (так называемые машины желания), о которых пишет Аелез и в которых нет места природной телесности человека, где проявляют себя довоплощенное бытие «бестелесного желания» и «обезличенные потоки информации» (П. Вирильо, Ф. Киттлер).

Хансен считает, что Аелез безосновательно разрывает связь аффектации с действиями человеческого тела (как «центра неопределенности», по Бергсону) и связывает ее с «образом-движением».

Хансен делает вывод, что именно сенсомоторика тела индетерминирует уникальное человеческое восприятие, поскольку именно человеческое тело является «центром индетерминации». Хансен, следуя Бергсону, желает освободить телесность от зависимости от кадра, продемонстрировать, что образ есть производная аффективной телесности зрителя.

Хансен выявляет новый тип чувствования, когда субъект определяется отнюдь не разумом, но своей телесностью, именно она центрирует и конституирует его. Теле- 
сный уровень чувствования, аффективное переживание/опыт полнее и аккуратнее отражает характеристики индивидуальности, нежели процессы на более высоких уровнях сознания, как правило, подлежащих/подчиненных в своей работе разнообразным опосредующим режимам сигнификации.

Аффективность представляется Хансену как «режим получения телесного опыта, который выступает в качестве посредника между индивидуальным и доиндивидуальным, телесным и его “виртуальными” потенциями» (Hansen, 2004: 7).

Хансен, анализируя идеи Бергсона и Аелеза, приходит к выводу, что «не может быть никакого восприятия без аффектации (хотя может быть аффектация без перцепции): аффективность задает интервал в рамках телесного времени-пространства, интервал между действием того или иного сенсорного органа и действием тела на этот орган. Аффективность, таким образом, есть воздействие тела на само себя. <...> В этом смысле аффектация образует возможный набор ощущений (аффективность)» (там же: 225).

Поскольку аффективность «выбирает» нужное телу из ощущений перцепции, она несводима к какому-то определенному доминирующему ощущению (визуальному, звуковому и пр.), она «выявляет всю полноту возможностей - мультимодальность» (там же: 226).

Такое понимание мультимодальности телесной аффектации как «внутреннего интервала» близко взглядам современного философа-когнитолога Б. Массуми, для которого аффект есть «восприятие самости индивида, ощущение жизни, способности к обновлению» (Massumi, 1995: 97).

Массуми в своих размышлениях о человеческой перцепции различает аффект и эмоцию. Аля Массуми аффект первичен, подсознателен, досубъективен, полисемичен и не заключен в чем-то конкретном; а эмоции зависят от обстоятельств, чаще осознаваемы и доступны осмыслению, их вызывает какой-то знакомый предмет/объект. Эмоция - это представление аффекта, который осознан субъектом или оформлен, «схвачен» сознанием субъекта. Субъект не может овладеть своими аффектами, но в большинстве случаев может совладать со своими эмоциями. По мысли Массуми, аффект открывает виртуальное пространство возможного: «аффекты это бесконечный набор виртуальных синестетических возможностей, выявляемых (функционально ограниченных) реальным существованием [субъекта]» (Massumi, 1995: 96).

В результате человеческое тело воздействует само на себя через собственную аффектацию, производя внутреннее эмоциональное пространство «я», не ограниченное перцепцией или работой какого-либо отдельного органа чувств.

На этом основании М. Хансен делает вывод, что современные технологии (начиная с кино и далее цифровые медиа) изменяют сами основания традиционного понимания сенсорного опыта человека, возвращая человеческой перцепции самостоятельный телесный, докогнитивный или, точнее, паракогнитивный (в котором отсутствуют привилегии одного ощущения над другим) статус. Гаптические и проприоцептивные ощущения от экранного изображения понимаются Хансеном не как ненормативная разновидность видения, визуального восприятия, но как самостоятельное телесное самоаффектирование.

Это задает своеобразный вектор әстетической мысли, позволяющий по-новому интерпретировать кинопроизведения и становящийся базисом для эстетики постцифрового искусства в XXI в. 


\section{ЭКРАННЫЕ ИСКУССТВА \\ И ТЕАЕСНО-ОРИЕНТИРОВАННАЯ МЕТОАОАОГИЯ}

В последнее время исследователями предпринимаются попытки применить энактивистскую и телесно-обусловленную методологию для анализа произведений современного искусства.

В кинотеории такие попытки предпринимают В. Галлезе, $\Lambda$. Маркс, В. Собчак, А. Баркер (Gallese, Guerra, 2012; Marks, 2002; Sobchack, 1992; Barker, 2009) в цифровом и интерактивном искусствах М. Хансен (Hansen, 2004) и др. Они выступают против традиции рассмотрения аудиовизуального произведения как текста и исследуют, как смыслы и значения кинофильмов и цифровых произведений складываются благодаря телесной, мускулатурной, висцеральной активности зрителя.

Мультисенсорный и телесный уровень взаимодействия между зрителями и визуальными образами в произведениях кинематографа и фотографии исследует Э. Эсрок (Esrock, 2001). Она рассматривает случаи, когда зритель, вступая в диалог с произведением, может полностью раствориться в нем, так что перестают ощущаться границы между зрителем и произведением в опыте «соматической переинтерпретачии» образов (там же: 234).

При том что этот опыт «слияния» может происходить и досознательно, по мнению исследовательницы, он может и представляться сознанию. Эсрок приводит в пример работу фотохудожника П. Странда (под названием «Leaves» (1929). Предлагая всмотреться в прямые линии изображенных на фотографии листьев растений, Эсрок обращает внимание на то, что в некоторых случаях зритель может испытывать ощущение, что «линии проходят через его собственное тело» (там же: 237).

Эсрок связывает зрительные ощущения с телесными ощущениями осязания и внутренней плотности. Визуальные качества изображения - текстура, цветовой баланс, настроение, тональные контрасты могут вызывать синестетические ощущения «телесного испытания» произведения.

По мнению Э. Эсрок, зрение и касание - два взаимосвязанных чувства в опыте восприятия: «Будучи направленным на взаимодействие с реальным миром, осязание требует наличия внешнего объекта, и зрение предлагает его, чтобы ментально “ощупывать” зафиксированный визуально объект. Но осязание так же поставляет субъективные переживания самого прикосновения. В этом случае ментальное касание стимулируется видимым объектом. Тело осязает видимый объект. Следовательно, это двоякий процесс, когда касание ощущается как само по себе, так и в форме осязания внешнего объекта. Комбинация этих ощущений позволяет преодолеть физическое расстояние между визуально фиксируемым объектом и зрителем, делая осязание видимого объекта субъективным, телесно переживаемым в границах тела субъекта. Воспринимать - это ощущать объект частью себя или, иначе, ощущать себя частью объекта» (там же: 236).

Обращаясь к опыту феноменологии, ряд современных исследователей киноискусства представляют концепции «мультисенсорного кино»или «телесного кино» (Pethö, 2015; Elsaesser, Hagener, 2009). Эти концепции признают чрезвычайную важность самого акта телесного восприятия кино и мультисенсорного, гаптического воздействия фильмов, снимающего дистанцию между зрителем и экранным обpaзом.

В. Собчак, $\Lambda$. Маркс, Аж. Баркер обращаются к философским идеям Мерло-Понти, исследуя способы, с помощью которых смыслы и значения складываются и фор- 
мулируются через телесные, мускульные и висцеральные воздействия визуальных произведений (фильмов, видео, фотографий и пр.).

Так, канадская исследовательница $\Lambda$. Ю. Маркс под влиянием идей А. Ригля заключает, что в кинематографе и видеоискусстве встречаются произведения, при восприятии которых глаз функционирует как орган касания. Она утверждает, что зрительскому восприятию некоторых видов экранных произведений свойственна «гаптическая визуальность» (baptic visuality), которая означает, что внимание зрителя направлено на само восприятие, не на какие-либо конкретные образы или детали изображения, а на фактурную целостность изображения, как если бы внимание зрителя «растекалось» по плоскости пространства экрана, а не задерживалось на концентрации на чем-то конкретном, что видимо на поверхности. Такие «гаптические образы» (baptic images) лишь частично похожи на фигуры или изображения и позволяют зрителю прочувствовать текстуру образа, его материальное присутствие, а не его значение или реальный репрезентируемый референт. Маркс указывает: «Вместо того, чтобы демонстрировать объект таким, какой он есть, гаптическое кино вопрошает само существование объекта, предлагая зрителю принять участие в его воображаемом конструировании» (Marks, 2002: 16).

Маркс стремится описать качества выразительности, позволяющие вывести экранное искусство за границы визуальности и аудиовизуальности и продемонстрировать, как аудиовизуальные образы кинофильмов (прежде всего экспериментальное и авторское кино) могут стимулировать неаудиовизуальные, «нерепрезентационные» ощущения касания (тактильные ощущения), запаха, вкуса, которые непосредственно с самими образами не связаны.

Маркс, продолжая идеи Ж. Аелеза и Ф. Гваттари, фиксирует специфический способ рецепции произведений современного экранного искусства - принцип телесного «скольжения», навигации «по краю фактуры», а не узнавание образных референтов реальности; телесная сопричастность зрителя и образа, а не интерпретация смыслов, вложенных кем-либо в образ: "следует двигаться по граням объекта, а не пьтаться постичь или “интерпретировать" его, как нас учит традичионное искусствоведение» (там же: хііi).

Используя последние данные научных исследований, свидетельствующие о мультисенсорной природе человеческих ощущений, $\Lambda$. Р. Антюнс (Antunes, 2014) утверждает, что просмотр кинофильма (как и любого другого визуального произведения) основан не только на визуальном и звуковом восприятии, но и активирует проприоцептивные, термоцептивные и вестибюлярные ощущения. Антюнс показывает, что человеческая перцепция мультисенсорна, мультимодальна и работает благодаря нескольким одновременно функционирующим каналам получения и анализа поступающей информации.

Приводя в пример фильм С. Кубрика «Космическая одиссея 2001 года» (1968), Антюнс показывает, как просмотр фильма активирует проприоцептивные ощущения, вызывающие сокращения мышц и сенсорно-моторные движения зрителя в ответ на то, что он видит. Несмотря на то что статья рассматривает этот әффект на примере кино, тот же механизм может функционировать при восприятии любого аудиовизуального произведения.

Недавние открытия в нейрокогнитивных исследованиях показали, что благодаря механизму работы так называемых зеркальных нейронов человеческий мозг настроен на мгновенное и дорефлексивное постижение смысла наиболее важных действий 
и эмоциональных состояний. На опытах с приматами было доказано, что за это мгновенное распознание действий отвечают клетки мозга, расположенные в лобных долях вентральной премоторной коре мозга в секторе $\Phi 5$. Это так называемые визомоторные нейроны или зеркальные нейроны, ответственные за собственные действия организма и одновременно за восприятие действий других организмов, в том числе и воображаемых или предполагаемых действий. Мгновенная активация этих нейронов позволяет мозгу координировать собственные действия и ощущения от восприятия осуществления действий других людей. Более подробно механизмы функционирования зеркальных нейронов описали в своих работах Г. Риззолетти (Rizzolatti, Craighero, 2004; Rizzolatti, Corrado, 2006), М. Якобони и А. Фадига (Grasping the intentions ... , 2005; Premotor Cortex ..., 1996).

Теория «зеркальных нейронов» доказывает, что человек воспринимает мир не только посредством идентификации, эмпатии, не только через понимание мотивов поступков и действий окружающих людей, но и через нейрологические процессы, которые позволяют испытывать действия людей или каких-либо объектов (как реальных, так и изображаемых на экране или картине) как свои собственные.

Объединив нейрокогнитивные и нейрофизиологические данные с феноменологической теорией, исследователи (например, В. Галлезе) предложили концепцию «телесно воплощенной симуляции» (embodied-simulation, ES) (Gallese, 2003, 2005ab; Gallese, Sinigaglia, 2011), которая, в противоположность традиционной когнитивной теории восприятия, представляет собой бессознательную, дорациональную форму опытного понимания индивидом других людей/объектов через внутреннее перенесение «на себя» их наблюдаемых действий. Аействия другого переживаются наблюдателем, как будто бы он или она исполняли похожее действие или переживали похожую эмоцию или чувство. И системы зеркальных нейронов управляют этим механизмом.

Теория «телесной симуляции» обеспечивает научные, нейробиологические основания для того, чтобы понимать специфику интерперсональных и объектных взаимодействий и мультимодальных коммуникаций, в том числе в области современного искусства. Учет роли визомоторных нейронов позволяет переосмыслить традиционные теории восприятия искусства, и прежде всего визуальных искусств.

В рамках набирающей популярность в гуманитарных науках концепции әнактивизма (энактивного познания) субъект познания рассматривается как активный: он активно встраивается в среду, его когнитивная активность совершается посредством его «вдействования» в среду или ее энактивирования. Познание, причем и восприятие, и мышление, и воображение, сопряжено с действием (Князева, 2014: 8). В своей книге «Арево познания» теоретики энактивизма У. Матурана и Ф. Варела формулируют это в виде афоризма: «Всякое действие есть познание, всякое познание есть действие» (Матурана, Варела, 2001: 23).

Восприятие понимается в его синкретичной связи с действием, психомоторной активностью (активностью психики и тела) и активностью ума, концептуализацией. Ааже ментальная активность понимается сторонниками энактивизма как действие или как движение. Модель восприятия мира субъектом для энактивизма - это касание, а не видение или слушание. Умственная активность человека напрямую связывается с сенсомоторным действием.

А. Ноэ разработал концепцию восприятия как телесного действия. Видение - это телесная активность; оно сопровождается движением глаз, головы и тела. Восприятие и перцептивное сознание зависят от способностей действовать и способностей 
мыслить. Восприятие есть некий тип одновременно моторной активности тела и мыслительной активности ума. «Осознание мира вокруг нас - это то, что мы делаем: мы энактивируем его - с помощью самого мира - в нашей динамической жизненной активности. Сознание - это то, что случается с нами» (Nöе, 2010: 64). Аля энактивизма восприятие - это не только процесс, происходящий в мозге, но способ активности тела, встраивающегося и «вдействующегося» в осваиваемую им среду.

Перенося эту концепцию на анализ современных аудиовизуальных произведений, можно предположить, что взаимодействие между произведением и зрителем может рассматриваться как взаимное энактивирование трех «телесностей»: тела зрителя, «тела» произведения и тела автора. Цифровые изображения в работах современных художников активизируют работу тела зрителя, стимулируя зрителя к активному вдействованию в визуальные объекты и выявляя тем самым аффективный уровень субъективного восприятия произведений современного искусства.

Учет мультисенсорности воздействия образа влечет необходимость пересмотра традиционной методологии оценки художественных произведений. Новый подход позволяет определить мультисенсорность кино как опыт зрительской телесной активности, а не только как способ интерпретации текстов и осмысления авторского высказывания.

Мультисенсорная методика анализа аудиовизуальных произведений могла бы стать альтернативой традиционнным «герменевтической» и семиотической методологии анализа кинотекстов: от интереса к анализу качеств и ценностей аудиовизуальных текстов как «объектов искусства» (с позиции критика / искуссствоведа / стороннего наблюдателя) интерес смещается к анализу процессов зрительского использования кинотекстов (с позиции участника и рецепиента опыта). Анализируются, например, проявления додискурсивной человеческой аффектации через мультисенсорное восприятие образа в кинематографических произведениях. В дополнение к традиционному текстуально-семиотическому анализу предлагается рассматривать произведение современного искусства как средство зрительского вдействования в иллюзорную или пространственно локализируемую среду.

\section{ЗАКАЮЧЕНИЕ}

Современные открытия в нейрокогнитивной науке, кинотеории и визуальной психологии показывают: зритель никогда не пассивен в своем кресле, существует сильная взаимосвязь между восприятием сцен в кино и реальным восприятием мира (Anderson, 1996).

Визуальные образы тогда - не әстетизированные изображения реальности, но объекты, инициирующие активное зрительское действие, как интерпретационное, так и физическое. Функция таких образов-объектов - операционная, иная, нежели у оригинальных произведений искусства, аудиовизуальных продуктов или литературных сочинений. Художник-классик создавал тексты для интерпретации. Некоторые современные художники (М. Крюгер, М. Шоу, М. Бенаюн, А. Рокеби, Р. Аозано-Хэммер и др.) создают аудиовизуальные пространства в своих цифровых произведениях для ментальных и физических действий зрителей/пользователей. Воздействие таких произведений основано не столько на глубине, информационной наполненности и цельности художественных образов, сколько на возможностях действий зрителя/пользователя в процессе мультисенсорного взаимодействия с пространством произведения. 
Визуальные образы расширяют возможности зрительской самореализации через активность, делают разнообразнее его «внутренние действия»в перцептивном (аффективном) опыте проживания «внутреннего пространства». Воспринимая экранные произведения, зритель энактивирует пространство произведения, открывая для себя возможности действий собственного тела.

Таким образом, проблема телесности, «телоцентризма», «соматизма» выходит на передний план искусствоведческой и в целом гуманитарной рефлексии, поскольку позволяет искать пути преодоления смысловой избыточности культурных объектов и художественных произведений.

\section{СПИСОК АИТЕРАТУРЫ}

Балаш, Б. (1925) Видимый человек: Очерки драматургии фильма / пер. с нем. К. И. Шутко. М. : Всерос. пролеткульт. 88 с.

Беньямин, В. (1996) Произведение искусства в эпоху его технической воспроизводимости. Избранные эссе : пер. с нем. / под. ред. Ю. А. Здорового. М. : Медиум. 240 с.

Бергсон, А. (1992) Собрание сочинений : в 4 т. : пер. с фр. / предисл. И. И. Блауберг. М. : Московский клуб. Т. 1. Опыт о непосредственных данных сознания. Материя и память. 325 с.

Бергсон, А. (1998) Творческая эволюция : пер. с фр. М. : Канон-Пресс ; Кучково поле. 384 с.

Аелез, Ж. (2004) Кино. Кино 1: Образ-движение. Кино 2: Образ-время / пер. с фр. Б. Скуратова ; под ред. О. Аронсона. М. : Ад Маргинем. 623 с.

Азига Вертов: Киновещь (2016) [предисл. А. Щербенка] // Формальный метод: Антология русского модернизма. / сост. С. Ушакин. Москва ; Екатеринбург : Кабинетный ученый. Т. 2. Материалы. 934 с.

Князева, Е. Н. (2014) Энактивизм: новая форма конструктивизма в эпистемологии. М. ; СПб. : Центр гуманитарных инициатив ; Университетская книга. 352 с.

Матурана, У. Р., Варела, Ф. Х. (2001) Арево познания. Биологические корни человеческого понимания : пер. с англ. М. : Прогресс-Традиция. 224 с.

Мерло-Понти, М. (1999) Феноменология восприятия / пер. с фр. под ред. И. С. Вдовиной, С. $\Lambda$. Фокина. СПб. : Ювента ; Наука. 608 с.

Морен, Э. (1996) Кино, или воображаемый человек (фрагменты)/ пер. с фр. М. Ямпольского // Киноведческие записки. № 25-28. С. 193-203.

Савчук, В. В. (2010) Метафора поворота в философии // Философские науки. № 10. С. 135-150.

Эпштейн, М. Н., Тульчинский, Г. А. (2006) Философия тела. Тело свободы. СПб. : Алетейя. $432 \mathrm{c.}$

Anderson, J. D. (1996) The Reality of Illusion: An Ecological Approach to Cognitive Film Theory. Carbondale and Edwardsville: Southern Illinois University Press. 200 p.

Antunes, L. R. (2014) Neural Correlates of the Multisensory Film Experience // Neuroscience and Media: New Understandings and Representations / Grabowski, N. (ed.). New York, NY. ; London : Routledge. P. 46-62.

Barker, J. M. (2009) The Tactile Eye: Touch and the Cinematic Experience. University of California Press. 208 p. $232 \mathrm{p}$.

Elsaesser, T., Hagener, M. (2009) Film Theory: An Introduction Through the Senses. Routledge.

Esrock, E. (2001) Touching art: intimacy, embodiment and the somatosensory system // Consciousness and Emotion, 2: 2. P. 233-254.

Gallese, V. (2003) The Manifold Nature of Interpersonal Relations: The Quest for a Common Mechanism // Philosophical Transactions of the Royal Society of London. Vol. 358, issue 1431. P. 517-528. DOI: 10.1098/rstb.2002.1234

Gallese, V. (2005a) Intentional Attunement: The Mirror Neuron System and its Role in Interpersonal Relations [Электронный ресурс] // Interdisciplines. URL: http://www.interdisciplines.org/ mirror/papers/1/printable/paper (дата обращения: 10.10.2016). 
Gallese, V. (2005b) Embodied Simulation: From Neurons to Phenomenal Experience // Phenomenology and the Cognitive Sciences. Vol. 4, issue 1. P. 23-48. DOIi:10.1007/s11097-005-4737-z

Gallese, V., Sinigaglia, C. (2011) What Is So Special with Embodied Simulation? // Trends in Cognitive Sciences. Vol. 15, issue 11. P. 512-519. DOI: 10.1016/j.tics.2011.09.003

Gallese V., Guerra M. (2012). Embodying Movies: Embodied Simulation and Film Studies. Cinema: Journal of Philosophy and the Moving Image, 3: 183-210, 2012.

Guattari, F. (1995) Chaosmosis: an ethico-aesthetic paradigm. Bloomington/Indianapolis: Indiana University Press. 136 p.

Grasping the intentions of others with one's own mirror neuron system (2005) / Iacoboni M., Molnar-Szakacs I., Gallese V., Buccino G., Mazziotta J. C., Rizzolatti G. // PLoS Biology. № 3. P. 529-535.

Hansen, M. B. N. (2004) New Philosophy for New Media. MIT Press. 361 p.

Marks, L. U. (2002) Touch: Sensuous Theory and Multisensory Media. University of Minnesota Press. 259 p.

Massumi, B. (2002) Parables for the Virtual: Movement, Affect, Sensation. Durham: Duke University Press. 336 p.

Massumi, B. (1995) The Autonomy of Affect // Cultural Critique. № 31. The Politics of Systems and Environments. Part II. P. 83-109. DOI: 10.2307/1354446

Nöe, A. (2010) Out of our Heads: Why You are Not Your Brain, and Other Lessons from the Biology of Cognition. Farrar, Straus \& Giroux. 232 p.

Pethö, Á. (2015) The Cinema of Sensations. Cambridge Scholars Publishing. 395 p.

Rizzolatti, G., Craighero, L. (2004) The Mirror Neuron System// Annual Review of Neuroscience. Vol. 27. P. 169-192.

Rizzolatti, G., Corrado, S. (2006) Mirrors in the Brain: How Our Minds Share Actions and Emotions / trans. F. Anderson. Oxford : Oxford University Press. 256 p.

Premotor Cortex and the Recognition of Motor Actions (1996) / Rizzolatti G., Fadiga L., Gallese V., Fogasi, L. // Cognitive Brain Research. № 3. P. 131-141.

Sobchack, V. (1992) The Address of the Eye: A Phenomenology of Film Experience. Princeton, NJ : Princeton University Press. 354 p.

Sobchack, V. (2004) Carnal Thoughts: Embodiment and Moving Image Culture. Berkeley, CA : University of California Press. 340 p.

The Brain Is the Screen: An Interview with Gilles Deleuze (2000) // The Brain Is the Screen: Deleuze and the Philosophy of Cinema / Flaxman, G. (ed.). Minneapolis : University of Minnesota Press. 408 p. P. 365-375.

Aата поступления: 13.10 .2016 2.

BODY-ORIENTED APPROACH TO THE ANALYSIS OF WORKS OF SCREEN ARTS

A. A. DENIKIN

INSTITUTE of CINEMA AND TELEVISION (GITR); RUSSIAN StATE UNIVERSITY FOR THE HUMANITIES

The article analyzes the basic provisions of foreign studies of the films in terms of body-oriented approach. The article examines philosophical works by H. Bergson, M. Merleau-Ponty, D. Kamper, H. Maturana, B. Massumi, F. Varela, M. Hansen and others. The body-oriented approach and the concept of «bodily-engendered simulation» make it possible to analyze the role of affective, bodily experience in the interpretation of audiovisual works. It is argued that the «visuality» of the world is formed by more internal bodily elements, rather than the abstract power of sight, and it is the body of the viewer and their activity that specify the conditions for the perception of images.

The article considers a new kind of sensory perception, whereby the subject is not defined by the mind, but by their embodiment, which in its turn centres and constitutes the subject. The bodily level of sensory perception, the affective experience reflect the individual's characteristics more fully and accurately, than the processes on the higher levels of consciousness. As a rule, the latter are submissive in their work to various mediating modes of signification. As a result the human body affects itself 
through its own affectation, producing the inner emotional space «I», not limited by the perception or the work of a certain sense.

The theory of «bodily simulation» provides scientific, neurobiological foundations for understanding the specifics of interactions between the viewer, the author, and the work of screen art. Possibilities of multisensory perception of film productions are discussed. It is proposed to consider the reception of a film as a process of the viewer's activity in the illusory and spatially localized environment.

Visual images broaden the viewer's opportunities for self-realization with the help of bodily activity, enliven their «inner actions» in the perceptive (affective) experience of inhabiting their inner space. By perceiving a film, the viewer enacts the screen space, discovering opportunities for the actions of their own body. Perception is understood in its syncretic connection with action, psychomotor activity (activity of the psyche and body) and the activity of the mind, conceptualization. Even mental activity is perceived as an action or as a movement.

The article concludes that the problem of embodiment, "body centrism», «somatism» is at the forefront of art criticism and, in general, humanitarian reflection, because it allows you to look for ways of overcoming the semantic redundancy of cultural objects and works of art.

Keywords: body-oriented approach; haptic aesthetics; affectivity; affecting image; multimodality; mirror neurons; embodied simulation; enactivism; enactive cognition

\section{REFERENCES}

Balash, B. (1925) Vidimyi chelovek: Ocherki dramaturgii fil' ma, transl. by Germ. By K. I. Shutko. Moscow, Vseros. proletkul't. 88 p. (In Russ.).

Ben'iamin, V. (1996) Proizvedenie iskusstva $v$ epokbu ego tekbnicheskoi vosproizvodimosti. Izbrannye esse, transl. by Germ., ed. Iu. A. Zdorovyi. Moscow, Medium. 240 p. (In Russ.).

Bergson, A. (1992) Sobranie socbinenii : in 4 vol., transl. by Fr., preface I. I. Blauberg. Moscow, Moskovskii klub. Vol. 1. Opyt o neposredstvennykb dannykb soznaniia. Materiia i pamiat'. 325 p. (In Russ.).

Bergson, A. (1998) Tvorcheskaia evoliutsiia, transl. by Fr. Moscow, Kanon-Press, Kuchkovo pole. 384 p. (In Russ.).

Delez, Zh. (2004) Kino. Kino 1: Obraz-dvizhenie. Kino 2: Obraz-vremia, transl. by Fr. By B. Skuratova, ed. by O. Aronsona. Moscow, Ad Marginem. 623 p. (In Russ.).

Dziga Vertov: Kinoveshch' (2016), preface by A. Shcherbenka. In: Formal' nyi metod: Antologiia russkogo modernizma, comp. S. Ushakin. Moscow, Ekaterinburg, Kabinetnyi uchenyi. Vol. 2. Materialy. 934 p. (In Russ.).

Kniazeva, E. N. (2014) Enaktivizm: novaia forma konstruktivizma v epistemologii. Moscow, St. Petersburg, Tsentr gumanitarnykh initsiativ, Universitetskaia kniga. 352 p. (In Russ.).

Maturana, U. R. and Varela, F. Kh. (2001) Drevo poznaniia. Biologicheskie korni chelovecheskogo ponimaniia, transl. by Engl. Moscow, Progress-Traditsiia. 224 p. (In Russ.).

Merlo-Ponti, M. (1999) Fenomenologiia vospriiatiia, transl. by Fr., ed. I. S. Vdovina and S. L. Fokin. St. Petersburg, Iuventa, Nauka. 608 p. (In Russ.).

Moren, E. (1996) Kino, ili voobrazhaemyi chelovek (fragmenty), transl. by Fr. by M. Iampol'skii. Kinovedcheskie zapiski, no. 25-28, pp. 193-203. (In Russ.).

Savchuk, V. V. (2010) Metafora povorota v filosofii. Filosofskie nauki, no. 10, pp. 135-150. (In Russ.).

Epshtein, M. N. and Tul'chinskii, G. L. (2006) Filosofiia tela. Telo svobody. St. Petersburg, Aleteiia. 432 p. (In Russ.).

Anderson, J. D. (1996) The Reality of Illusion: An Ecological Approach to Cognitive Film Theory. Carbondale and Edwardsville, Southern Illinois University Press. 200 p.

Antunes, L. R. (2014) Neural Correlates of the Multisensory Film Experience. In: Neuroscience and Media: New Understandings and Representations, Grabowski, N. (ed.). New York, London, Routledge. P. 46-62. 
Barker, J. M. (2009) The Tactile Eye: Touch and the Cinematic Experience. University of California Press. 208 p.

Elsaesser, T. and Hagener, M. (2009) Film Theory: An Introduction Through the Senses. Routledge. 232 p.

Esrock, E. (2001) Touching art: intimacy, embodiment and the somatosensory system. Consciousness and Emotion, 2: 2, pp. 233-254.

Gallese, V. (2003) The Manifold Nature of Interpersonal Relations: The Quest for a Common Mechanism. Philosophical Transactions of the Royal Society of London, vol. 358, issue 1431, pp. 517-528. DOI: $10.1098 / \mathrm{rstb} .2002 .1234$

Gallese, V. (2005a) Intentional Attunement: The Mirror Neuron System and its Role in Interpersonal Relations. Interdisciplines [online] Available at: http://www.interdisciplines.org/mirror/ papers/1/printable/paper (access date: 10.10.2016).

Gallese, V. (2005b) Embodied Simulation: From Neurons to Phenomenal Experience. Phenomenology and the Cognitive Sciences, vol. 4, issue 1, pp. 23-48. DOI:10.1007/s11097-005-4737-z

Gallese, V. and Sinigaglia, C. (2011) What Is So Special with Embodied Simulation? Trends in Cognitive Sciences, vol. 15, issue 11, pp. 512-519. DOI: 10.1016/j.tics.2011.09.003

Gallese V. and Guerra M. (2012). Embodying Movies: Embodied Simulation and Film Studies. Cinema: Journal of Philosophy and the Moving Image, no. 3, pp. 183-210.

Guattari, F. (1995) Chaosmosis: an ethico-aesthetic paradigm. Bloomington/Indianapolis: Indiana University Press. $136 \mathrm{p}$.

Grasping the intentions of others with one's own mirror neuron system (2005) / Iacoboni M., Molnar-Szakacs I., Gallese V., Buccino G., Mazziotta J. C. and Rizzolatti G. PLoS Biology, no. 3, pp. 529-535.

Hansen, M. B. N. (2004) New Philosophy for New Media. MIT Press. 361 p.

Marks, L. U. (2002) Touch: Sensuous Theory and Multisensory Media. University of Minnesota Press. 259 p.

Massumi, B. (2002) Parables for the Virtual: Movement, Affect, Sensation. Durham, Duke University Press. 336 p.

Massumi, B. (1995) The Autonomy of Affect. Cultural Critique, no. 31. The Politics of Systems and Environments. P. II. Pp. 83-109. DOI: 10.2307/1354446

Nöe, A. (2010) Out of our Heads: Why You are Not Your Brain, and Other Lessons from the Biology of Cognition. Farrar, Straus \& Giroux. 232 p.

Pethö, Á. (2015) The Cinema of Sensations. Cambridge Scholars Publishing. 395 p.

Rizzolatti, G. and Craighero, L. (2004) The Mirror Neuron System. Annual Review of Neuroscience, vol. 27, pp. 169-192.

Rizzolatti, G. and Corrado, S. (2006) Mirrors in the Brain: How Our Minds Share Actions and Emotions, trans. By F. Anderson. Oxford, Oxford University Press. 256 p.

Premotor Cortex and the Recognition of Motor Actions (1996) / Rizzolatti G., Fadiga L., Gallese V. and Fogasi, L. Cognitive Brain Research, no. 3, pp. 131-141.

Sobchack, V. (1992) The Address of the Eye: A Phenomenology of Film Experience. Princeton, NJ., Princeton University Press. 354 p.

Sobchack, V. (2004) Carnal Thoughts: Embodiment and Moving Image Culture. Berkeley, CA., University of California Press. 340 p.

The Brain Is the Screen: An Interview with Gilles Deleuze (2000). In: The Brain Is the Screen: Deleuze and the Philosophy of Cinema, Flaxman, G. (ed.). Minneapolis, University of Minnesota Press. 408 p. Pp. 365-375.

Submission date: 13.10 .2016$.

Аеникин Антон Анатольевич - кандидат культурологии, доцент, профессор кафедры звукорежиссуры и музыкального искусства Института кино и телевидения (ГИТР); доцент кафедры кино и современного искусства Российского государственного гуманитарного университе- 
та. Адрес: 123007, Россия, г. Москва, Хорошевское шоссе, д. 32А. Тел.: +7 (495) 721-38-50. Эл. aspec: oficial@list.ru

Denikin Anton Anatolievich, Candidate of Culturology, Associate Professor, Professor, Department of Sound Engineering and Music Art, Institute of Cinema and Television (GITR); Associate Professor, Department of Cinema and Modern Art, Russian State University for the Humanities. Postal address: 32A, Khoroshevskoe Highway, Moscow, Russian Federation 123007. Tel.: +7 (495) 721-38-50. E-mail: oficial@list.ru 